\title{
Integrated CMOS 3D Microstrip Patch Antenna Prototype for Wireless Energy Harvesting
}

\author{
H. Deshpande ${ }^{1}$ and K. Karande ${ }^{2}$ \\ ${ }^{1}$ Assistant Professor, SKN Sinhgad college of Engineering, Korti Pandharpur 413304 Dist-Solapur, Maharashtra \\ 2 Professor, SKN Sinhgad college of Engineering, Korti Pandharpur 413304 Dist-Solapur, Maharashtra \\ \{hrushikesh102@gmail.com; Kailashkarande@yahoo.co.in\}
}

\begin{abstract}
Economic growth of any country depends on its ratio of population growth and basic requirement merit. The Energy storage and Energy production these are the two basic problems arises due to it in the development of country. This paper focuses on this current scenario and proposes a flexible 3D cube model which is responsible for multiple frequency reception. The model focuses by this paper is RF energy harvesting model basically used for reception of 4 frequencies $915 \mathrm{MHz}, 2.4 \mathrm{GHz}, 2.67 \mathrm{GHz}, 5.8 \mathrm{GHz}$. This is the first multiple frequency design as per our literature survey of 4 cubic face with asymmetric patch structure and top surface is feed point for combing all $\mathrm{AC}$ power. At $915 \mathrm{MHz}$ and $2.4 \mathrm{GHz}$ power obtained is $9 \mathrm{db}$ and $12 \mathrm{db}$ respectively. The antenna AC power is then feed to integrated CMOS 5 Stage rectifier for obtaining DC power which is used in Wireless Energy Harvesting as a solution for Energy Crisis.
\end{abstract}

Keywords: WEH (Wireless Energy Harvesting), End Fire Array, Differential Patch Design, Fringing Field.

\section{Introduction}

Remote sensing devices are becoming recent widely used domain in recent engineering trends. These devices does not require internal power or voltage circuitry to work their applications .Such application works on the platform of energy harvesting where the ambient energy is converted into electrical energies to charge the remote or local station electronic devices[1]. One of the best methods for such passive device is to harvest energy from propagating Radio Frequency (RF) which is widely available in GSM, DTV, Wi-Fi and tolling system applications. The Wireless Energy Harvesting (WEH) and International Microwave Theory and Techniques Society (MTT-S) states the term Energy Harvesting as "The process of conversion of ambient energy into electrical energy as the practice of capture, accumulation and storage of unexploited energy from circumambient environmental sources". In modern society RF wireless network performs a vital role of collecting and distribution of information .These structures involves radio and television bands, GSM and UMTS cellular Network. The prior goal is to investigate with proper energy Harvesting system and Circuit design, the ultimate goal is to collect power of different RF spectrum signal which can be harvested to supply enough power to these passive devices. The functionality of this system depends on system design basically to achieve low power consumption and high efficiency [9][10]. This RF energy harvesting design is also suitable mainly for traditional battery replacements which is impractical and costs consuming. To satisfy all these aspects and use of naturally available ambient energy this paper proposes a model for RF energy harvesting, the collection of different frequency bands with throughput as power is achieved with the help of proper efficient antenna design with high gain. This paper uses one of the RF energy harvesting method and which is RF Energy harvesting with Antenna design. The main task models of design are efficient antenna design, design of high RF-DC conversion rectifier and power storage and voltage doublers circuit design. The power conversion mainly depends on transmission characteristics. The big challenge in design is transmission loss i.e. available power may loss or change with distance and gain of antenna [8]. The different researcher proposes various antenna design models which involve use of folded dipole, Microstrip, Yagi-Uda, Circular Patch antenna for Energy harvesting[6][7]. In RF energy harvesting antenna design input impedances, SWR, VSWR, antenna patterns its gain depend on position of director and reflector for high power output all these parameters are need to be checked for selection of antenna[11]. The basic project flow is as shown in Fig 1 below.

B. Iyer, S. Nalbalwar and R. Pawade (Eds.)

ICCASP/ICMMD-2016. Advances in Intelligent Systems Research.

Vol. 137, Pp. 679-687.

(C) 2017- The authors. Published by Atlantis Press

This is an open access article under the CC BY-NC license (http://creativecommons.org/licens)es/by-nc/4). 


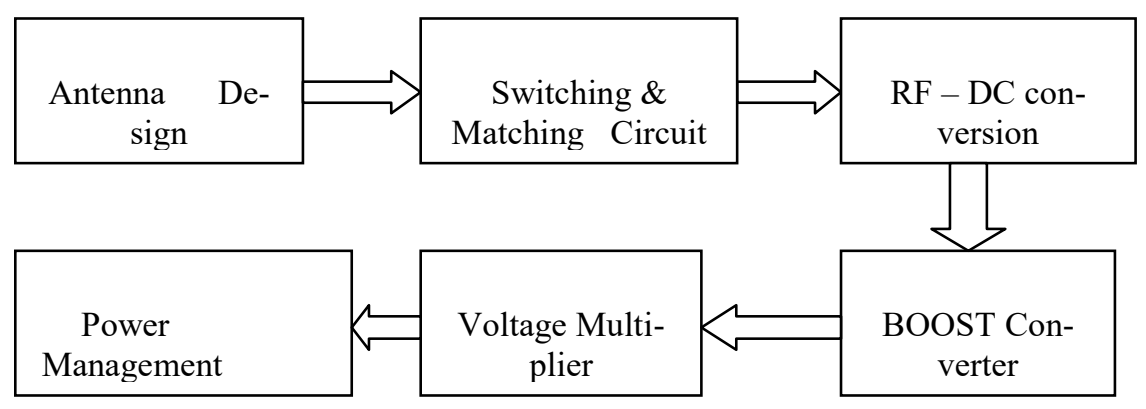

Fig. 1. Basic RF Energy Harvesting System

The proposed design consists of 3D cube antenna design which is the single antenna consisting 4 patch designs. These patches are of type End-fire array and $4 \times 4$ patch design. The differential and Mender slot design can be used for better antenna gain. The FR4 and Duroid surface are used for substrate of characteristics FR4 with $\varepsilon r=4.4$, and RT/Duroid $5880 \mathrm{\varepsilon r}=2.2$ substrate. The overall assembly simulates and design in HFSS and AC power gain is achieved from antenna. This power feed as input power to Rectifying circuit which is CMOS 5 stage of voltage doubler design. The actual $3 \mathrm{D}$ cube design structure is as shown in figure 2 below which is actual project foot prints in which all the four faces of cube indicates different patches as 1,2,3,4, for 4 frequencies reception and top face acts as common feed point of all face from where AC power can feed to rectifier design .

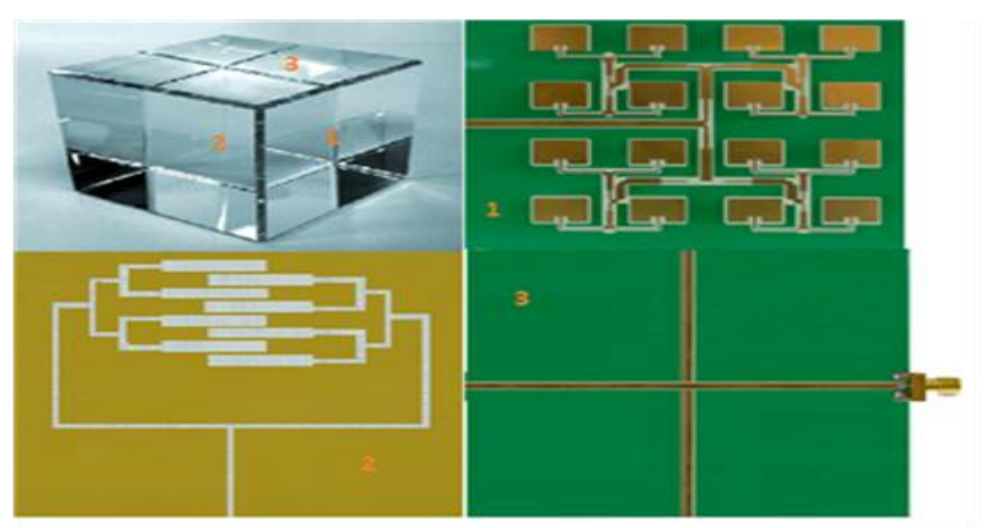

Fig. 2. Proposed cubic structure of Microstrip antenna

Objective of this paper is to discuss various sections. The paper is organized into VII sections including this introduction. Section I is based on Introduction, Section II describes Microstrip 4x4 patch array design for dual frequencies. Section III gives End fire array design and its parameter for remained 2 frequencies. Section IV Integrated CMOS Design for rectification which is of 5 stages. Section V describes details of obtained simulation results of Ansoft HFSS software. Section VI gives details about paper feature its conclusion and references which are used for this design.

\section{Microstrip Patch 4x4 Array Design}

The Microstrip antennas are low profile, conformable to planar and non planar surfaces, simple and inexpensive to fabricate using modern printed-circuit technology, mechanically robust when mounted on rigid surfaces, compatible with MMIC (Monolithic Microwave Integrated Circuit). As in microwave frequencies TEM mode propagation fails to propagate under wave guide structure mainly due to transversal electric and magnetic fields. As all the field components inside a wave guide Ex, Ey, Hx and Hy are becomes zero. Similarly, in Microstrip patch structure Antenna Proposed cubic structure of Microstrip antenna radiates power which is mainly radiate in fringing field structure.

Microstrip antennas consist of a very thin ( $\mathrm{t}=$ thickness $)(\mathrm{t}<<\lambda 0$, where $\lambda 0$ is the free-space wavelength) metallic strip (patch) placed a small fraction of a wavelength ( $\mathrm{h}<<\lambda 0$, usually $0.003 \lambda 0 \leq \mathrm{h} \leq 0.05 \lambda 0$ ) above a ground plane. The Microstrip patch is designed so its pattern maximum is normal to the patch (broadside radiator). For a rectangular patch, the length $\mathrm{L}$ of the element is usually $\lambda 0 / 3<\mathrm{L}<\lambda 0 / 2$. The strip (patch) and the ground 
plane are separated by a dielectric sheet called substrate.

There are numerous substrates that can be used for the design of Microstrip antennas, and their dielectric constants are usually in the range of $2.2 \leq \varepsilon r \leq 12$. The ones that are most desirable for good antenna performance are thick substrates whose dielectric constant is in the lower end of the range because they provide better efficiency, larger bandwidth, loosely bound fields for radiation into space, but at the expense of larger element size. Thin substrates with higher dielectric constants are desirable for microwave circuitry because they require tightly bound fields to minimize undesired radiation and coupling, and lead to smaller element sizes; however, because of their greater losses, they are less efficient and have relatively smaller bandwidths. Since Microstrip antennas are often integrated with other microwave circuitry, a compromise has to be reached between good antenna performance and circuit design. The antenna design proposed by this design uses both line feed and inset line feed techniques. The basic Microstrip patch antenna parameters are calculated as follows in (1) (2) (3) (4) (5) and (6).

The width of the patch as in (1):

$$
\mathrm{W}=\frac{\mathrm{c}[1 / \sqrt[2]{(\mathscr{E}+1) / 2}]}{2 \mathrm{fo}}
$$

The length of the patch given in (2):

$$
\mathrm{L}=\frac{\mathrm{c}}{2 \mathrm{fo} \sqrt{\varepsilon \mathrm{e}}}-2 \Delta \mathrm{L}
$$

Where $\varepsilon_{\mathrm{e}}$ and $\Delta \mathrm{L}$ are given as(3)(4)

$$
\begin{aligned}
& \varepsilon_{\mathrm{e}}=\frac{\varepsilon_{\mathrm{r}}+1}{2}+\frac{\varepsilon_{\mathrm{r}}-1}{2} \frac{1}{\sqrt{1+\frac{12 \mathrm{~h}}{\mathrm{~W}}}} \\
& \Delta \mathrm{L}=0.412 \mathrm{~h} \frac{\left(\varepsilon_{e}+0.300\right)\left(\frac{w}{h}+0.264\right)}{\left(\varepsilon_{e}-0.258\right)\left(\frac{w}{h}+0.800\right)}
\end{aligned}
$$

The input impedance is calculated as Zin in (5)

$$
\operatorname{Zin}(R)=\cos 2\left(\frac{\pi R}{L}\right) \operatorname{Zin}(0)
$$

The wave length of substrate is $\chi_{\mathrm{s}}$ is given as (6),

$$
\chi=\mathrm{c} / \mathrm{f} \sqrt{ } \mathrm{\varepsilon r})
$$

\begin{tabular}{|c|c|c|c|c|c|}
\hline $\begin{array}{l}\text { Sr. } \\
\text { No }\end{array}$ & Frequency & $\begin{array}{l}\text { Array } \\
\text { Type }\end{array}$ & Substrate & Length & Width \\
\hline 1 & $2.4 \mathrm{GHz}$ & \multirow{2}{*}{$\begin{array}{l}\text { End Fire } \\
\text { Array }\end{array}$} & \multirow{2}{*}{$\begin{array}{l}\text { FR4 } \\
(\varepsilon r=4.2, \text { thick- } \\
\text { ness }=1.6 \mathrm{~mm})\end{array}$} & 15 & 63.5 \\
\hline 2 & $2.67 \mathrm{GHz}$ & & & 14.48 & 57.17 \\
\hline 3 & $5.8 \mathrm{GHz}$ & \multirow{2}{*}{$\begin{array}{l}4 \times 4 \text { patch } \\
\text { array }\end{array}$} & \multirow{2}{*}{$\begin{array}{l}\mathrm{RT} / \text { Duroid } 5880 \\
(\varepsilon \mathrm{r}=2.2, \text { thick- } \\
\text { ness }=1.5 \mathrm{~mm})\end{array}$} & 15.54 & 21.43 \\
\hline 4 & $935 \mathrm{MHz}$ & & & 106.5 & 125.7 \\
\hline
\end{tabular}

The mathematical parameters are based on Relative permittivity (cr), height (h) and central/resonating frequency (fc). In our design we use 4 resonating frequencies and 2 dielectric substrates. The mathematical calculation is as follows Table 1,

Table 1. Different Frequency Parameter Estimation 
Thus as shown in table I the Microstrip patch as above, in which the frequency $2.4 \mathrm{GHZ}$ and $2.67 \mathrm{GHz}$ are designed using End-fire array and frequency $5.8 \mathrm{GHz}$ and $915 \mathrm{MHz}$ are designed using $4 \mathrm{x} 4$ patch array. For $4 \mathrm{x} 4$ patch array we are using inset feed array technique in which antenna is fed in the center of patch width (w). Due to this structure current is low at the ends of a half wave patch and increases current magnitude towards center along with dimension (L). In our design we are uses inset fed to match impedance of feed line to patch without need of any additional matching impedance. Generally, patch length is of $(\chi=2 \mathrm{~L})$ i.e. patch is half wavelength long. Consider phase changes at $\mathrm{R}$ distance, $2 \pi \mathrm{R} /(2 \mathrm{~L})=\pi \mathrm{R} / \mathrm{L}$. As the distribution of current is assumed to sinusoidal in nature. The departure by distance $\mathrm{R}$ increases current by Cos $(\pi \mathrm{R} / \mathrm{L})$ and Voltage $(\mathrm{V})$ will be decrease by same amount. So our feed line input impedance (Zin) is given by Zin= V/I can be given as in (5). This inset feed design is as in Fig 3,
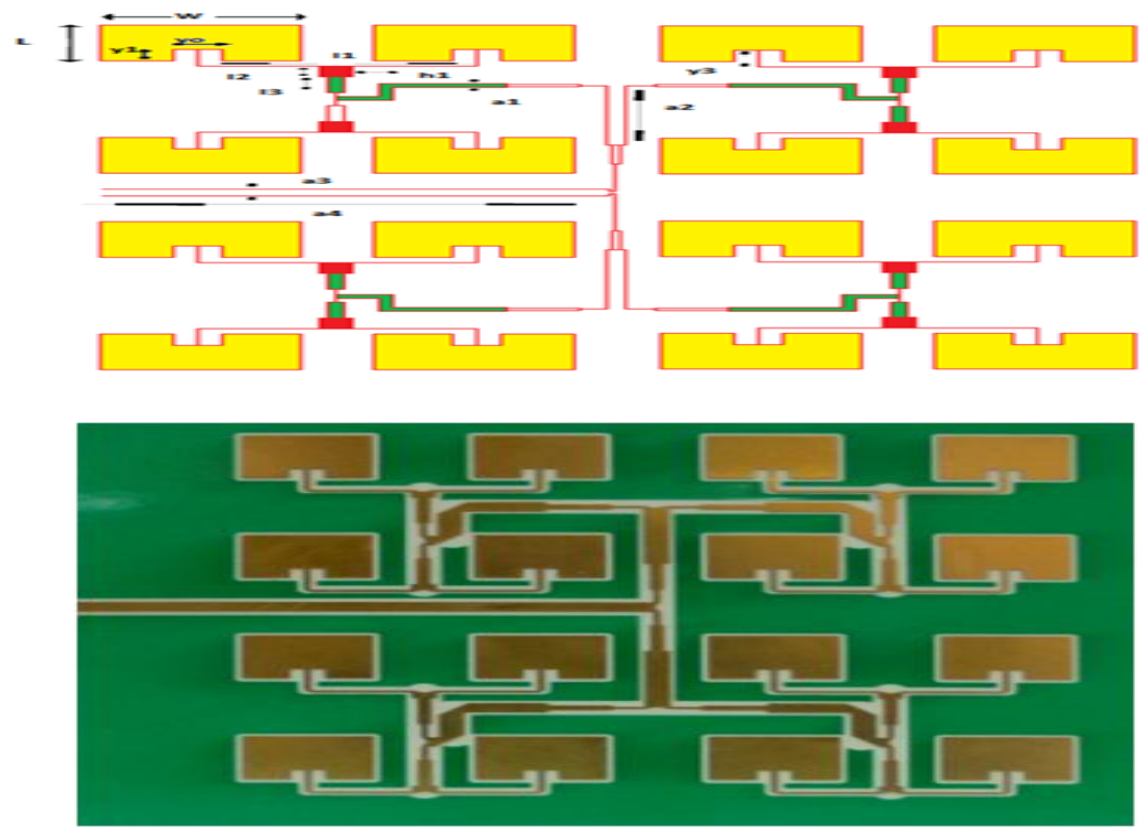

Fig 3. Microstrip 4x4 Actual Design with substrate.

The dimensions of patch are as follows, it will depend on feed input impedance which is $50 \Omega$ for $2 \times 1$ and $100 \Omega$ for $4 \times 1$.Now for $5.8 \mathrm{GHz}$ calculations and $935 \mathrm{MHz}$ calculations are as follows in Table 2,

Table 2 . 5.8 GHz 4x4 Patch Array \& 935MHz 4x4 Patch Array Parameters

\begin{tabular}{lllllll}
\hline Name & $\begin{array}{l}\text { Value } \\
(\mathrm{mm})\end{array}$ & Name & $\begin{array}{l}\text { Value } \\
(\mathrm{mm})\end{array}$ & $\begin{array}{l}\text { Value } \\
(\mathrm{mm})\end{array}$ & Name & $\begin{array}{l}\text { Value } \\
(\mathrm{mm})\end{array}$ \\
\hline $\mathrm{W}$ & 19.43 & 12 & 1.4 & 125.7 & 12 & 12.53 \\
$\mathrm{~L}$ & 12.54 & 13 & 4.1 & 105.5 & 13 & 27.4 \\
yo & 3.8 & $\mathrm{~h} 1$ & 2.1 & 25.5 & $\mathrm{~h} 1$ & 14.3 \\
y1 & 3.8 & $\mathrm{a} 1$ & 0.3 & 25.75 & $\mathrm{a} 1$ & 6.2 \\
y2 & 3.8 & $\mathrm{a} 2$ & 34.1 & 25.75 & $\mathrm{a} 2$ & 246.2 \\
y3 & 7.7 & $\mathrm{a} 3$ & 3.3 & 53.12 & $\mathrm{a} 3$ & 25.12 \\
11 & 40.22 & $\mathrm{a} 4$ & 55.8 & 253.4 & $\mathrm{a} 4$ & 268.3 \\
\hline
\end{tabular}

The final 1 cubic side patch for $5.8 \mathrm{GHz}$ is as follows in Fig. 3 right side, it consisting of $4 \times 4$ patch array. The same patch with above size is used for $935 \mathrm{MHz}$.

\section{Microstrip Patch End Fire Array Design}

In our design we are representing 4 center frequency designs in which two frequencies are designed using end fire array technique. As direction of radiation may be combined with $4 \times 4$ patch array receiving radiation, to avoid this we are using end fire design because in end fire array design the direction of radiation of main beam is depend on only phase difference (a), between array elements. Due to this the main beam can be varies in any 
direction. Consider $\mathrm{N}$ elements which are placed equally. In our model we are interspaced them by distance d. therefore direction of wave described by the angle $(\theta)$ given as $(7)$,

$$
\operatorname{AF}(\theta)=\sum_{i=0}^{N-1} w(n) e^{-j k n d s i n(\theta)}
$$

Where $\mathrm{k}=2 \pi / \lambda$ is the wave number and $\lambda$ is the wave length, In $w(\mathrm{n}) e^{-j k n d \sin (\theta)}$, here phase factor is $\alpha$ and it is adjusted as in the element weight, $w(n)$. If the desired steering angle is $\theta 0$ the phase difference must be adjusted such that when $\theta=\theta 0$

As in (8) (9)

$$
\Psi=\mathrm{kd} \sin (\theta)+\alpha=\mathrm{kd} \sin (\theta 0)+\alpha=0
$$

Thus

$$
\alpha=-\mathrm{kd} \sin (\theta 0)
$$

The normalized factor is (10),

$$
\mathrm{AFn}=\frac{\cos \mathrm{N} \pi \frac{\mathrm{d}(\sin \theta-\sin \theta 0)}{\lambda}}{\mathrm{N} \pi \frac{\mathrm{d}(\sin \theta-\sin \theta 0)}{\lambda}}
$$

so $\Psi=0$ is end fire operation at $\theta 0=90$ and $\theta=0$ the phase difference given as(11) (12),

$$
\begin{aligned}
& \alpha=-\mathrm{kd} \sin (90)=-\mathrm{kd} \\
& \alpha=-\mathrm{kd} \sin (-90)=\mathrm{kd}
\end{aligned}
$$

For efficient end fire array operation front to back ration must be high. It can be reduced by minimizing granting lobes below zero. In end fire array granting lobes occurs in (13),

$$
\frac{\mathrm{d}[\sin (\theta)-1]}{\lambda}=\mathrm{n}, \mathrm{n} \varepsilon \mathrm{N}
$$

The operating frequency in mn mode is in (14)

$$
\left.\operatorname{fr}(m, n)=\frac{c}{2 \sqrt{\varepsilon r}} \sqrt{\left(\frac{m}{L}\right.}\right) 2+\left(\frac{n}{w}\right) 2
$$

Where $\mathrm{m}, \mathrm{n}$ are the integers in which TM mode is exist, $\mathrm{c}$ is velocity of light,

$\mathrm{W}$ and $\mathrm{L}$ are width (15)

$$
\mathrm{w}=1 / 2 \sqrt{2 \lambda /(\varepsilon r+1)}
$$

and length of patch is described in (16),

$$
\mathrm{L}=[\mathrm{c} / 2 \mathrm{fr} \sqrt{\mathrm{\varepsilon r})}]=\chi / 2
$$

As wave propagates in transversal magnetic field therefore there exists (TMmn) mode for wave propagation. Thus the $4 \times 4$ end fire array structure designed in this design is as follows in Fig.4, 

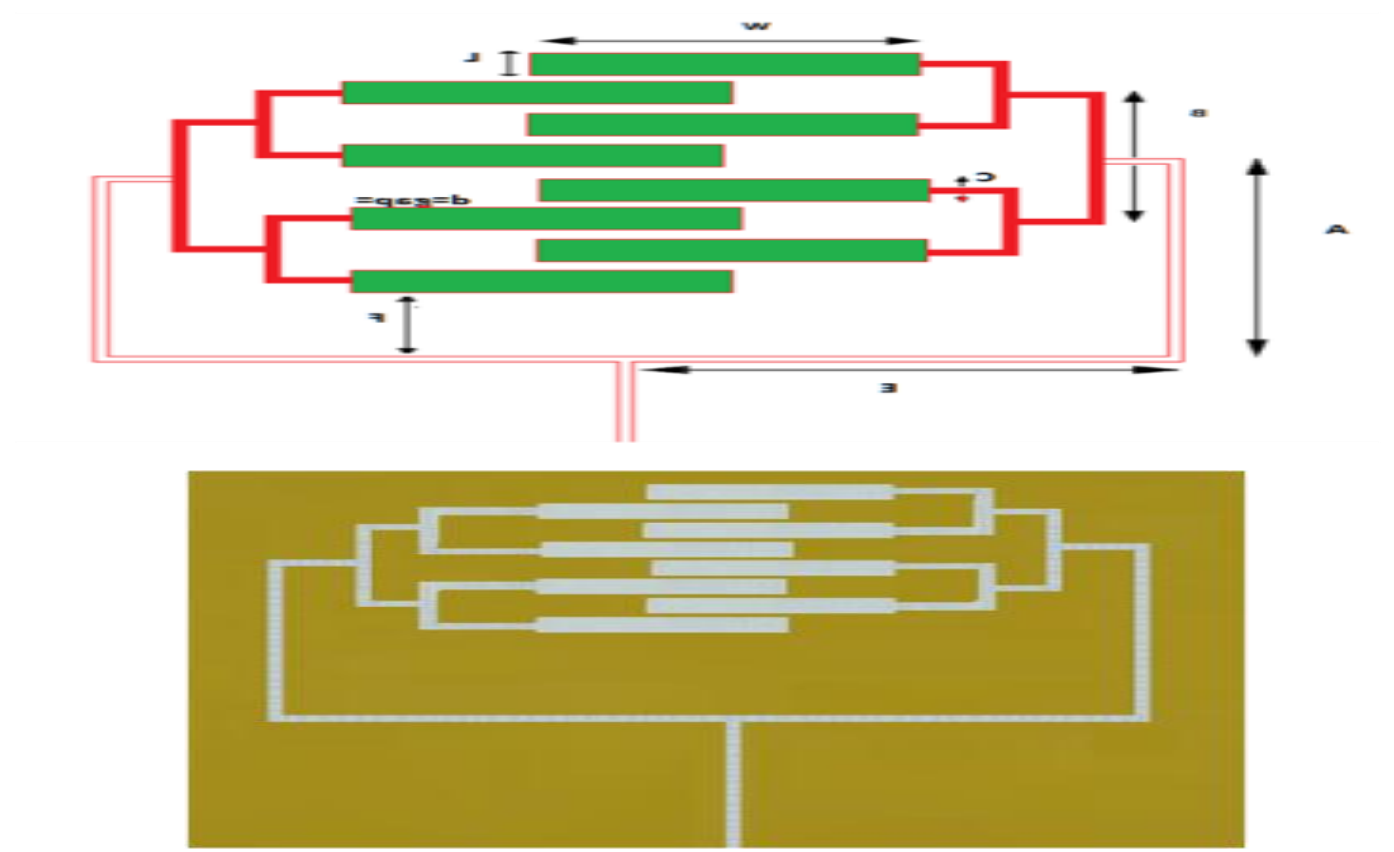

Fig .4. Proposed design for End Fire array \& Actual Design of End Fire array

Consider frequency $\mathrm{f} 1=2.4 \mathrm{GHZ}$, it has $\chi=125 \mathrm{~mm}$ and $\mathrm{f} 2=2.67 \mathrm{GHz}$ it has $\chi=112.35 \mathrm{~mm}$. Thus End fire array parameter calculation is as given as, for $2.4 \mathrm{GHz}$ and $2.67 \mathrm{GHz}$ parameters given as Table 3 ,

Table 3. $2.4 \mathrm{GHz} 4 \times 4$ End Fire Array \& $2.67 \mathrm{GHz} 4 \times 4$ End Fire Patch Array Parameters

\begin{tabular}{llllcll}
\hline Name & $\begin{array}{l}\text { Value } \\
(\mathrm{mm})\end{array}$ & Name & $\begin{array}{l}\text { Value } \\
(\mathrm{mm})\end{array}$ & $\begin{array}{c}\text { Value } \\
(\mathrm{mm})\end{array}$ & Name & $\begin{array}{c}\text { Value } \\
(\mathrm{mm})\end{array}$ \\
\hline $\mathrm{W}$ & 61.5 & $\mathrm{C}$ & 5.25 & 55.17 & $\mathrm{C}$ & 4.61 \\
$\mathrm{~L}$ & 14 & $\mathrm{D}$ & 4 & 12.48 & $\mathrm{~d}$ & 3.49 \\
$\mathrm{~A}$ & 104 & $\mathrm{E}$ & 92.75 & 93.37 & $\mathrm{E}$ & 83.26 \\
$\mathrm{~B}$ & 86.5 & $\mathrm{~F}$ & 20.25 & 79.64 & $\mathrm{~F}$ & 20.09
\end{tabular}

Finally all the feeds of 4 Surfaces of cube are combine together which gives input as power to the rectifier circuit. The top surface of cube represent as combine feeder as all these antennas are acts as receiver antenna which receives input different frequencies and gives output from fed. The cubic top surface of combined surface is given in Fig.5,

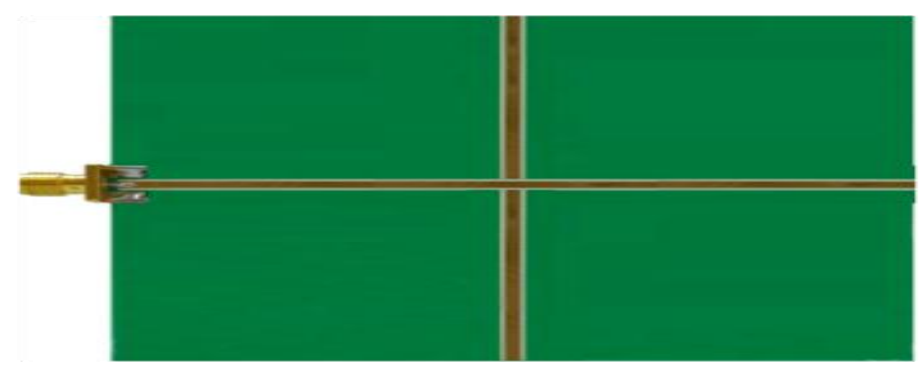

Fig 5. Top integrated face of Feeds

Table 4. Cube Surface Details

\begin{tabular}{|c|c|c|c|}
\hline Sr.No. & Surface & Frequency & Patch Type \\
\hline 1 & LHS1 & $2.4 \mathrm{GHz}$ & End Fire Array \\
\hline 2 & RHS 1 & $2.67 \mathrm{GHz}$ & End Fire Array \\
\hline 3 & LHS2 & $5.8 \mathrm{GHz}$ & $\begin{array}{l}4 \times 4 \text { Rectangular } \\
\text { patch }\end{array}$ \\
\hline 4 & RHS2 & $935 \mathrm{MHz}$ & $\begin{array}{l}4 \times 4 \text { Rectangular } \\
\text { patch }\end{array}$ \\
\hline 5 & TOP & \multicolumn{2}{|c|}{ Combine all 4 Feeds } \\
\hline
\end{tabular}


The received output power is calculated as (17),

$$
\operatorname{Pr}=\mathrm{Pt} * \mathrm{Gt} * \mathrm{Gr} *(\chi / 4 \pi \mathrm{R})
$$

Where, Gt and Gr is antenna gains, $\chi$ are wave length of transmitted signal, Pt and Pr are transmitted and received powers. The combined feed length is analogous to length of cube plus side surface insertion [4][5]. The overall cubic design is above in Table 4.

\section{Integrated CMOS Rectifier Design.}

A CMOS 5 stage rectifier is used in design; voltage doubler is designed using Dickson Multiplier topology. Silicon based Schottky diode having threshold voltage of $230 \mathrm{mV}$ and diode capacitance of $0.26 \mathrm{pF}$ is chosen. At microwave frequency, the non-linear capacitance of the diode governs the maximum power transfer to the load and amplitude of the rectified output as input impedance of the rectifier changes with frequency. The impedance observed for a voltage doubler configuration was of capacitive nature at $2.67 \mathrm{GHz}$ and inductive at $5.8 \mathrm{GHz}$. Input impedance of the diode also changes with the input power as the dc operating point of the I-V curve moves in a non-linear fashion. Large variation of input impedance with input power and frequency makes designing a broadband conjugate matching network complex. Therefore, a resistive impedance matching network in fig. 5 is used to allow maximum power transfer

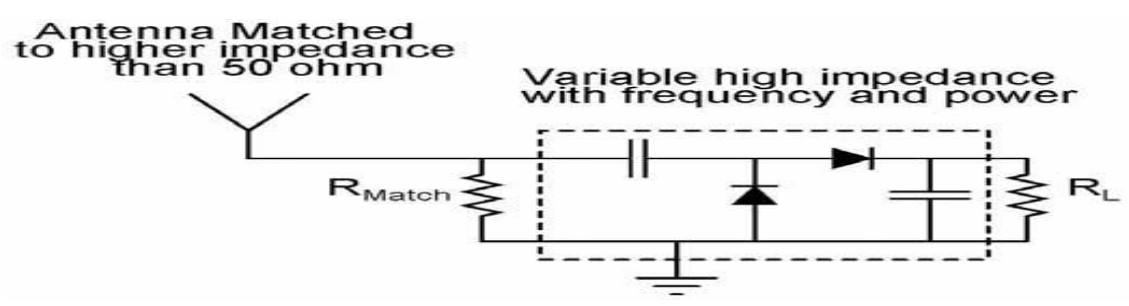

Fig. 5. Resistive Impedance Matching

The value of $\mathrm{R}$ Match depends on the input impedance of the antenna. The MSA designed at $2.67 \mathrm{GHz}$ is matched to $150 \mathrm{ohm}$ and MSA at $5.8 \mathrm{GHz}$ is matched to $120 \mathrm{ohm}$ instead of standard $50 \mathrm{ohm}$. This approach provides an approximate and simple matching between the antenna and rectifier.

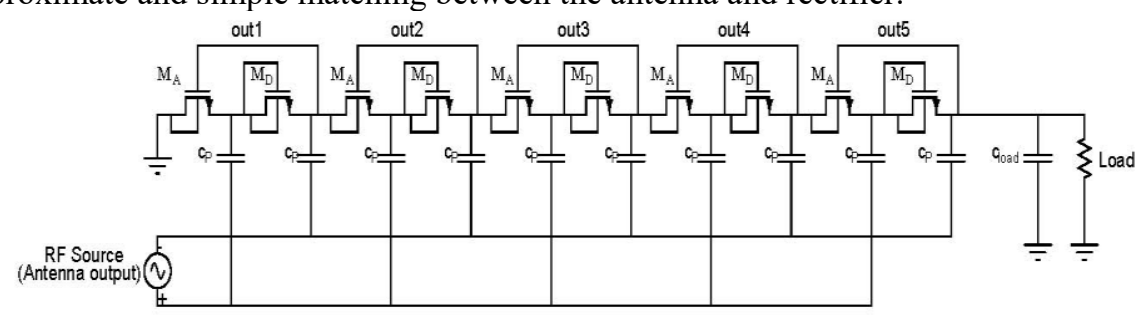

Fig.6. CMOS 5 Stage Rectifier Design

The proposed rectifier shown in Fig. 6 is designed using Cadence custom IC design flow in UMC180nm CMOS process. The simulations were performed on Spectrum RF. MA is a transistor with gate connected to the alternate node and MD is the transistor with drain connected gate. In the negative half cycle, MA is switched ON and it gets biased by the next node voltage. In the positive half cycle, MD is ON.

\section{Experimental Result.}

Antenna Gain parameters are analyzed as follows and the gain of antenna at $2.4 \mathrm{GHz}$ as shown in Fig 7(a),7(b). As shown in figure, It is the Experimental result of single patch gain of $2.4 \mathrm{GHZ} 4 \times 4$ patch, where the total tegration of design is in process for obtaining final antenna gain and giving as input feed to rectifier. The experimental result shows the antenna patch gain at central frequency $2.4 \mathrm{GHz}$ with $8.5 \mathrm{Gain}$ obtained in EM simulation of antenna design. Its 2D- Radiation pattern is as shown in figure 7(a) and 3-D Radiation pattern in 7(b). This simulated result shows the overall increase in gain of antenna with the use of $4 \times 4$ micro-strip patch structure. 


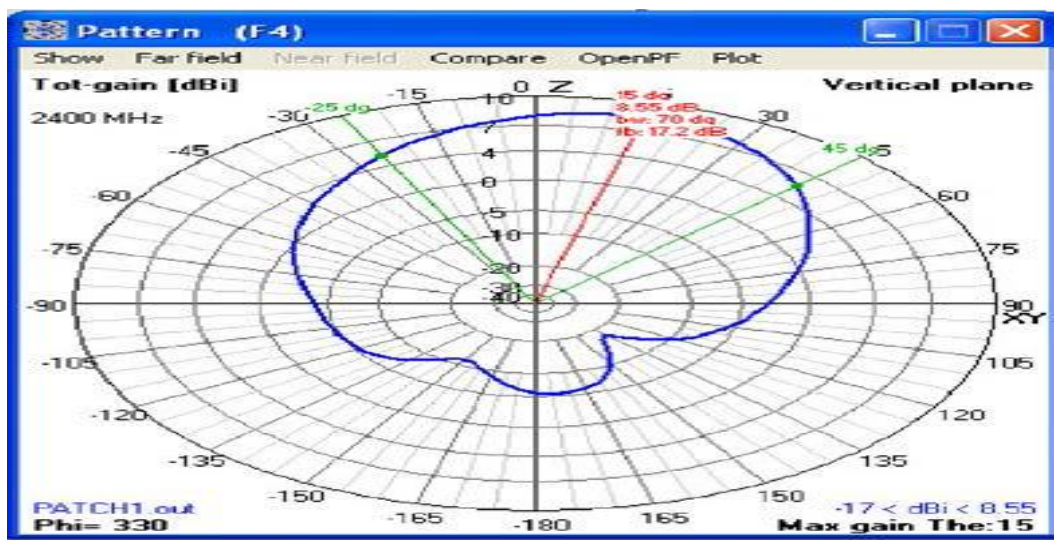

Fig. 7(a). Antenna 2-D Radiation pattern for $2.4 \mathrm{GHz}(8.55 \mathrm{~dB})$.

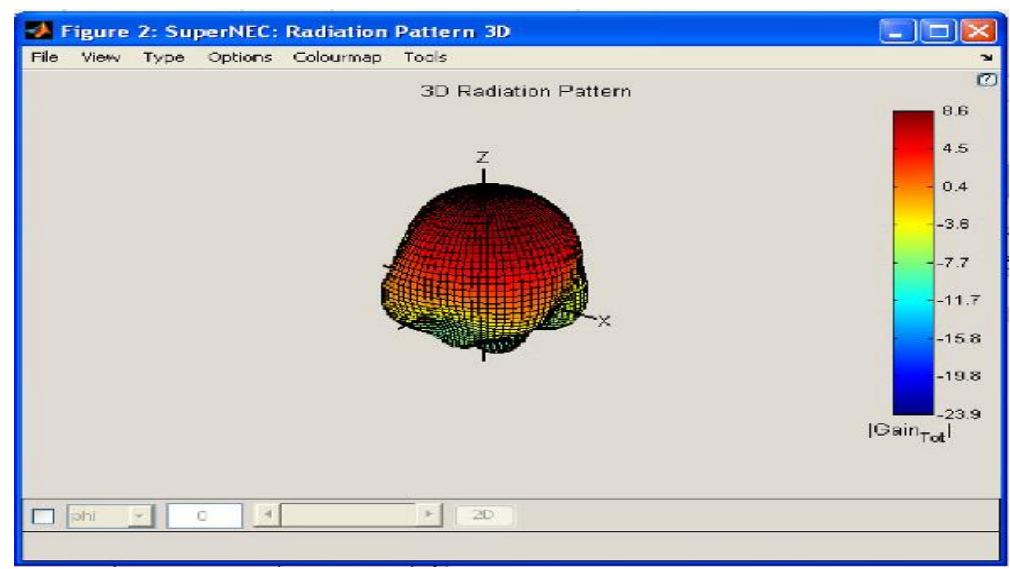

Fig. 7(b). Antenna 3-D Gain for 2.4GHz (8.6dB) .

\section{Conclusion.}

This paper proposes the multiple frequency 3D cube antenna design structure with two types of patch array combination. The received power output of antenna is given as input to rectifier circuit mainly consists of CMOS 5 stage design of Schotty diode. As Schotty diode requires very less turn on voltage causing high conversion efficiency of RF-DC power. This paper proposes a design of 4 frequency reception antenna which is used as RF energy harvesting efficient antenna. This is the first proposed design of multiple frequency $3 \mathrm{D}$ cube structure like origami antenna with 2 substrate 2 patch types and 4 frequencies. This paper proposes the first 3D multiple frequency model for RF reception. The single face $4 \times 4$ patch antenna is designed and simulated while the total integrated design for energy harvesting is proposed as future scope and it is under process.

\section{References}

[1] Mahima Arrawatia et.al "Differential Microstrip Antenna for RF Energy Harvesting” IEEE Transaction March 2015.

[2] G.P. Ramesh and A. Rajan, "Microstrip Antenna Design for RF Energy Harvesting” International Conference of communication and signal processing, IEEE 978-1-4799-3358-7, April 3-5 2014.

[3] L.C. Ong, et.al "Overview of Antenna for RF Energy harvesting” Institute for Infocom Research Agency for science Research Singapur,978-1-4673-5692-3, IEEE 2013

[4] Robert Scheeler et.al "A Dual-Frequency Ultralow-Power Efficient 0.5-g Rectenna" IMS 2013, IEEE Microwave, 1527-3342/14, Jan-Feb 2014. 
[5] Shabnam Ladan et.al "Highly Efficient Compact Rectenna for Wireless Energy Harvesting Application" IMS2012, IEEE Microwave, 1527-3342, Jan-Feb 2013.

[6] Mai Ali et.al "RF Energy Harvesting for Autonomous Wireless Sensor Network",978-1-4673-6040-1, IEEE 2013.

[7] Z. Zakaria et.al "Dual-Band Monopole Antenna for Energy Harvesting System" 978-1-4799-0156-2, IEEE (ISWTA) 2013.

[8] B. Chen, Y.-C. Jiao, F.-C. Ren, and L. Zhang, "Broadband monopole antenna with wideband circular polarization", Progress in Electromagnetic Research Letters, Vol. 32, pp. 19 - 28, 2012.

[9] Saswati Ghosh, "Ultra wideband Microstrip crossed monopole antenna as EMI sensor," Proceedings of National Symposium on Antennas and Propagation (APSYM) 2012, Cochin, India, pp. 67 - 70, 2012.

[10] S. Ghosh, B. K. Sarkar, "Design of Microstrip Crossed MonopoleAntenna for Ultra Wideband Communication," Proceedings of IEEEINDICON 2012, pp. 499 - 502, 2012.

[11] Mahima Arrawatia et.al "RF Energy Harvesting System from Cell Towers in 900 MHz Band", 978-161284-091-8, IEEE2011. 